\title{
Desenvolvimento agronômico e produtivo da soja sob diferentes doses de gesso agrícola
}

João Paulo Ascari ${ }^{1}$

Inês Roeder Nogueira Mendes²

\section{Resumo}

A soja é uma das principais culturas que movimentam o agronegócio brasileiro, por isso torna-se necessário adotar técnicas que influenciam a melhoria da qualidade do solo, como a gessagem. Com este estudo, objetivou-se verificar a influência de doses de gesso agrícola no desenvolvimento vegetativo e reprodutivo da cultura da soja. O experimento foi conduzido na Universidade do Estado de Mato Grosso, Campus Tangará da Serra. O delineamento experimental foi em blocos casualizados (DBC) com cinco tratamentos, sendo 0, 1, 2, 3 e $4 \mathrm{t} \mathrm{ha}^{-1}$ de gesso agrícola, com quatro repetições. Foi realizada a calagem e a gessagem aos 30 e 60 dias antes da semeadura, respectivamente. A semeadura foi realizada na segunda quinzena do mês de novembro com a cultivar P98Y30 em solo adubado no sulco. As avaliações foram realizadas em 10 plantas aleatórias no estádio fenológico $R_{9}$. Observou-se que as variáveis altura de planta, altura da primeira vagem, número de nós, número de vagens por planta, massa de 100 grãos e produtividade foram influenciadas de forma significativa pelas doses de gesso agrícola, em que os melhores resultados ocorreram na dose de $2 \mathrm{t} \mathrm{ha}^{-1}$, entretanto, o diâmetro do caule não sofreu influência. Com base no exposto, verificou-se que a dose de $2 \mathrm{t} \mathrm{ha}^{-1}$ de gesso agrícola apresentou o melhor efeito no desenvolvimento vegetativo e reprodutivo da soja.

Palavras-chave: Glycine max L. Gessagem. Produtividade.

\section{Introdução}

A cultura da soja (Glycine max L.) apresenta grande importância na economia brasileira, de tal modo que o Brasil é o segundo maior produtor mundial dessa oleaginosa e lidera o ranking das exportações mundiais. 0 estado de Mato Grosso destaca-se entre os demais estados nacionais, sendo responsável por cerca de $28 \%$ da produção brasileira, na safra 2015/2016 registrou produtividade média de $2.956 \mathrm{~kg} \mathrm{ha}^{-1}$ (COMPANHIA NACIONAL DE ABASTECIMENTO - CONAB, 2016).

Geralmente, é realizado plantio direto (PD) na grande maioria das áreas cultivadas com a cultura da soja. O não revolvimento do solo nesses sistemas geram impasses quanto à aplicação de corretivos nas camadas subsuperficiais, onde há alta concentração de alumínio tóxico, baixa disponibilidade de cálcio, magnésio, fósforo e outros nutrientes, formando uma camada que pode restringir o desenvolvimento das raízes e consequentemente reduzir a produtividade da cultura (BROCH et al., 2008).

A aplicação de gesso agrícola na superfície pode contribuir para reduzir esses efeitos negativos sobre o desenvolvimento das plantas, além de minimizar a magnitude da lixiviação de cálcio, magné-

1 Universidade do Estado de Mato Grosso, Campus de Tangará da Serra (MT), mestre em Ambiente e Sistemas de Produção Agrícola. Rodovia MT 358, km 07, Jardim Aeroporto, Tangará da Serra, Mato Grosso, Brasil, CEP: 78.300-000. E-mail: joaoascari@hotmail.com.

2 Universidade do Estado de Mato Grosso, Campus de Tangará da Serra (MT), mestranda em Ambiente e Sistemas de Produção Agrícola. E-mail: ynes_nogueira@hotmail.com. 
sio e potássio, garantindo maior efeito residual desses nutrientes no solo. Também pode promover a liberação de enxofre em profundidade, neutralizando o alumínio (ERNANI; RIBEIRO; BAYER, 2001).

O sistema radicular das plantas de soja explora um pequeno volume de solo, principalmente em solos de baixa fertilidade e em regiões onde ocorrem períodos de seca. 0 gesso agrícola pode ser utilizado para melhorar o ambiente para o crescimento da raiz nas camadas subsuperficiais do solo, o que contribui para que a cultura supere períodos de déficit hídrico e aumente a eficiência na absorção de nutrientes, melhorando o desempenho e produtividade (SORATTO; CRUSCIOL, 2008; CARVALHO; NASCENTE, 2014).

Os solos do cerrado apresentam boas respostas à aplicação de gesso agrícola, principalmente aqueles com baixa disponibilidade de cálcio e enxofre e alta toxidade de alumínio (TANAKA; MASCARENHAS, 2002). Aproximadamente $80 \%$ da área dessa região está sujeita a problemas de acidez subsuperficial do solo e períodos de seca frequentes, especialmente nos meses de janeiro e fevereiro, período crítico para o desenvolvimento de culturas da soja (RAMOS et al., 2006; CAIRES et al., 2008). Sousa (2004) e Cardoso et al. (2014) encontraram maior produtividade de soja cultivada em solos do cerrado quando realizada aplicação de gesso agrícola. No entanto, existem pesquisas como a de Caires et al. (2003) e Cherubin et al. (2010) que não verificaram efeitos desse corretivo na produção da soja.

A calagem é a técnica de correção do solo mais utilizada na agricultura, porém a gessagem é importante em circunstâncias específicas, como neutralizar alumínio em profundidade, lixiviar e liberar nutrientes nas camadas subsuperficiais do solo (RAIJ, 2008). Neste sentido, novos estudos são necessários para compreender os efeitos do gesso agrícola no solo e também no desenvolvimento das culturas, de acordo com as características edafoclimáticas de cada agroecossistema.

Por isso, espera-se que a técnica da gessagem melhore o desenvolvimento agronômico da cultura da soja, resultando em aumento de produtividade, em função da melhoria química do ambiente de exploração radicular e liberação de nutrientes no solo. Com base no exposto, o objetivo deste estudo foi verificar a influência de doses de gesso agrícola no desenvolvimento vegetativo e reprodutivo da cultura da soja.

\section{Material e métodos}

O experimento foi conduzido na área experimental da Universidade do Estado de Mato Grosso (UNEMAT), Campus de Tangará da Serra (MT), localizada na Rodovia MT 358. A região apresenta precipitação média anual de $1.800 \mathrm{~mm}$, temperatura média de $24,4^{\circ} \mathrm{C}$, umidade relativa do ar variando entre 70 e 80 \%, 440 m de altitude nas coordenadas geográficas 14³9'53" S, 57²5'46" W. O clima da região é classificado como tropical úmido megatérmico (AW), caracterizado por temperaturas elevadas, verão chuvoso e inverno seco (DALLACORT et al., 2011).

O solo da área experimental é classificado como LATOSSOLO VERMELHO Distrófico (EMPRESA BRASILEIRA DE PESQUISA AGROPECUÁRIA - EMBRAPA, 2013), com 48 \% de argila e topografia plana. Inicialmente, a área era composta por pastagem, na safra 2013/2014 foi cultivada com milho no sistema convencional. A análise de solo foi realizada no mês de setembro de 2014, foram coletadas 10 amostras simples de solo de forma aleatória na área; em seguida, foram homogeneizadas formando uma amostra composta, que foi encaminhada ao laboratório para realização das análises químicas (EMPRESA BRASILEIRA DE PESQUISA AGROPECUÁRIA - EMBRAPA, 2011). A Tabela 1 mostra os resultados da análise de solo antes da aplicação do calcário e do gesso agrícola. 
Tabela 1. Características químicas do solo nas camadas de 0 a $20 \mathrm{~cm}$ de profundidade antes da aplicação de calcário e gesso agrícola. Tangará da Serra (MT), UNEMAT, safra 2014/2015.

\begin{tabular}{|c|c|c|c|c|c|c|c|c|c|}
\hline \multirow{2}{*}{$\begin{array}{l}\text { Camada } \\
\mathrm{cm}\end{array}$} & \multirow{2}{*}{$\begin{array}{c}\mathrm{pH} \\
\mathrm{CaCl}_{2} \\
\end{array}$} & \multirow{2}{*}{$\begin{array}{l}\mathrm{pH} \\
\mathrm{H}_{2} \mathrm{O} \\
\end{array}$} & $\mathbf{P}$ & $\mathrm{K}$ & $\mathrm{Ca}$ & $\mathrm{Mg}$ & Al & H & СтC \\
\hline & & & \multicolumn{2}{|c|}{$---m g d^{-3}---$} & \multicolumn{5}{|c|}{ - } \\
\hline \multirow[t]{3}{*}{$0-20$} & 4,9 & 6,2 & 1,9 & 32 & 2,6 & 1,8 & 1,3 & 6,3 & 12,1 \\
\hline & MO & V & Sat. Al & $\mathrm{Zn}$ & $\mathrm{Cu}$ & $\mathrm{Fe}$ & $\mathrm{Mn}$ & $\mathrm{B}$ & S \\
\hline & $\mathrm{g} \mathrm{dm}^{-3}$ & $\%$ & $\%$ & ------ & ------ & $------m$ & $p^{-3}-{ }^{-----\cdot}$ & - & ------ \\
\hline $0-20$ & 37,8 & 37,0 & 29,01 & 0,8 & 6,6 & 75,0 & 73,0 & 0,82 & 10,5 \\
\hline
\end{tabular}

Fonte: Elaboração dos autores.

0 delineamento experimental foi em blocos ao acaso (DBC), com cinco tratamentos, sendo $0,1,2,3$ e $4 \mathrm{t} \mathrm{ha}^{-1}$ de gesso agrícola, com quatro repetições. Cada parcela foi constituída de cinco metros de comprimento por cinco metros de largura, com espaçamento entre linhas de 0,5 m. A área útil da parcela compreendeu as quatro linhas centrais, desconsiderando meio metro em cada extremidade como efeito de bordadura.

A calagem foi realizada 60 dias antes da semeadura da soja utilizando calcário dolomítico (28\% $\mathrm{CaO}, 20 \%$ MgO, PRNT $90 \%$ ) para elevar a saturação de bases a $60 \%$, sendo aplicados 3 t ha-1 $^{-1}$ de calcário, considerando os resultados da análise de solo e as recomendações de Sousa e Lobato (2004). A aplicação do gesso agrícola foi realizada 30 dias antes da semeadura, de modo que a aplicação foi feita a lanço, e a dose conforme cada tratamento. Logo em seguida foi realizada a incorporação do corretivo para acelerar as reações no solo (ERNANI; RIBEIRO; BAYER, 2001).

A semeadura foi realizada na segunda quinzena do mês de novembro de 2014 utilizando a cultivar de soja P98Y30, por ser uma cultivar recomendada para o cultivo na região, apresentar estabilidade produtiva, tolerar chuva em período de colheita e ter precocidade no ciclo. Foi realizado o tratamento de sementes com Carbendazin + Thiran e a inoculação com Bradyrhizobium japonicum no mesmo dia da semeadura.

A adubação corretiva e de semeadura foi realizada com $300 \mathrm{~kg} \mathrm{ha}^{-1}$ de $\mathrm{P}_{2} \mathrm{O}_{5}, 70 \mathrm{~kg} \mathrm{ha}^{-1}$ de $\mathrm{K}_{2} \mathrm{O}$. A adubação de cobertura foi realizada aos 30 dias após a semeadura (DAS) com $80 \mathrm{~kg} \mathrm{ha}^{-1} \mathrm{de} \mathrm{K}_{2} \mathrm{O}$, com base nas recomendações de Sousa e Lobato (2004). As fontes de nutrientes utilizadas foram superfosfato simples $\left(18 \% \mathrm{P}_{2} \mathrm{O}_{5}+16 \% \mathrm{Ca}\right)$, cloreto de potássio $\left(60 \% \mathrm{~K}_{2} \mathrm{O}\right)$. Foi feita aplicação foliar de macro e micronutrientes no estádio fenológico V8 com o produto Platon- $25^{\circledR}$.

O controle fitossanitário foi realizado conforme as recomendações de manejo da cultura, em que as aplicações foram feitas de forma manual com equipamento pressurizado de $\mathrm{CO}_{2}$, quando cada espécie atingiu o nível de controle.

As avaliações vegetativas e reprodutivas foram realizadas no estádio fenológico de $R_{8}$, foram selecionadas aleatoriamente 10 plantas da área útil. As variáveis analisadas foram altura de planta, altura da primeira vagem, número de vagens por planta, diâmetro do caule, número de nós (ZAPPAROLI et al., 2013).

A colheita foi feita no estádio fenológico de $\mathrm{R}_{9}$, em que as plantas da área útil foram colhidas e trilhadas. Em seguida, a umidade da massa de grãos foi corrigida para 13 \% (BRASIL, 2009), determinada a massa de 100 grãos (g) e produtividade ( $\left.\mathrm{kg} \mathrm{ha}^{-1}\right)$.

Foi realizado o teste de normalidade de Shapiro-Wilk e Correlação linear de Pearson, aplicando o pacote stats do software estatístico R. Após constatar distribuição normal de dados, realizou-se a análise de variância de dados paramétricos, utilizando o teste $\mathrm{F}$ para verificar a significância dos 
dados. Para as variáveis que apresentaram diferenças significativas, realizou-se análise de regressão utilizando o software SISVAR (FERREIRA, 2011) e a plotagem das Figuras com o software Excel.

\section{Resultados e discussão}

A partir da aplicação do teste de Shapiro-Wilk, verificou-se que todas as variáveis apresentaram distribuição normal de dados, deste modo aceita-se $\mathrm{H}_{0}=$ os dados seguem uma distribuição normal (Tabela 2).

Tabela 2. Resultado do teste de normalidade de Shapiro-Wilk (W) para altura de planta (AP), altura da primeira vagem $\left(A 1^{a} \mathrm{~V}\right)$, diâmetro do caule $(\mathrm{DC})$, número de nós $(\mathrm{NN})$, número de vagens por planta (NVP), massa de 100 grãos (MCG), produtividade de grãos (PROD) em detrimento de doses de gesso agrícola na cultura da soja. Tangará da Serra (MT), UNEMAT, safra 2014/2015.

\begin{tabular}{lcccc}
\hline \multirow{2}{*}{ Variáveis } & \multicolumn{4}{c}{ Shapiro-Wilk $(\mathbf{W})$} \\
\cline { 2 - 5 } & Valor de W & $\mathbf{N}^{0}$ amostras & Sig. (valor $-\mathbf{p})^{*}$ & Conclusão \\
\hline AP & 0,91624 & 20 & 0,0838 & sig $>0,05$ aceita-se $\mathrm{H}_{0}$ \\
A1 ${ }^{\text {av }}$ & 0,94779 & 20 & 0,3348 & sig $>0,05$ aceita-se $\mathrm{H}_{0}$ \\
DC & 0,94761 & 20 & 0,3323 & sig $>0,05$ aceita-se $\mathrm{H}_{0}$ \\
NN & 0,96927 & 20 & 0,7393 & sig $>0,05$ aceita-se $\mathrm{H}_{0}$ \\
NVP & 0,9122 & 20 & 0,0702 & sig $>0,05$ aceita-se $\mathrm{H}_{0}$ \\
MCG & 0,94464 & 20 & 0,2929 & sig $>0,05$ aceita-se $\mathrm{H}_{0}$ \\
PROD & 0,93723 & 20 & 0,2124 & sig $>0,05$ aceita-se $\mathrm{H}_{0}$ \\
\hline
\end{tabular}

*Nível de significância de $5 \%(p \leq 0,05)$.

Fonte: Elaboração dos autores.

Com base na análise de variância (Tabela 3), observou-se que as variáveis altura de planta, altura da primeira vagem, número de nós, número de vagens por planta, massa de 100 grãos e produtividade foram influenciadas de forma significativa pelas doses de gesso agrícola aplicadas na cultura da soja, entretanto, o diâmetro do caule não sofreu influência. Quanto ao diâmetro do caule, Zapparoli et al. (2013) também não verificaram diferenças significativas, registrando valores médios de 4,63 cm, inferior à média registrada no presente estudo $(5,55 \mathrm{~cm})$.

Tabela 3. Resultado da análise estatística, valores de FC, coeficiente de variação (CV) das fontes de variações (FV) para altura de planta (AP), altura da primeira vagem $\left(A 1^{a} \mathrm{~V}\right)$, diâmetro do caule (DC), número de nós (NN), número de vagens por planta (NVP), massa de 100 grãos (MCG), produtividade de grãos (PROD) em detrimento de doses de gesso agrícola na cultura da soja. Tangará da Serra (MT), UNEMAT, safra 2014/2015.

\begin{tabular}{|c|c|c|c|c|c|c|c|}
\hline $\begin{array}{l}\text { Fonte de } \\
\text { Variação }\end{array}$ & \multicolumn{2}{|c|}{-----------cm----------- } & $A 1^{a} \mathrm{~V}$ & $\begin{array}{l}\text { NN } \\
------U n\end{array}$ & $\begin{array}{r}\text { NVP } \\
\text { ades----- }\end{array}$ & $\begin{array}{c}\text { MCG } \\
\text {----g---- }\end{array}$ & $\begin{array}{l}\text { PROD } \\
\mathrm{kg} \mathrm{ha}^{-1}\end{array}$ \\
\hline $\begin{array}{l}\text { Doses de } \\
\text { gesso }^{1}\end{array}$ & $1,86^{\text {ns }}$ & $7,64 * *$ & $11,97^{* *}$ & $12,02 * *$ & $37,53 * *$ & $13,02 * *$ & $54,81^{* *}$ \\
\hline $\begin{array}{l}\text { Média } \\
\text { Geral }\end{array}$ & 5,55 & 51,65 & 6,87 & 14,55 & 102,90 & 22,30 & $2.278,08$ \\
\hline CV (\%) & 9,25 & 5,58 & 6,54 & 7,91 & 3,69 & 7,13 & 10,32 \\
\hline
\end{tabular}

${ }^{1}$ Valor do Fc, ** Significativo a $5 \%$, ns Não significativo pelo teste $\mathrm{F}$.

Fonte: Elaboração dos autores. 
Os maiores valores de altura de planta foram verificados nas doses de 2 e $3 \mathrm{t} \mathrm{ha}^{-1}$ de gesso agrícola, com 54,25 e 55,50 cm, respectivamente. O menor valor ocorreu na dose zero, com 45,25 cm (Figura 1). Os valores obtidos de altura das plantas estão abaixo do considerado ideal para a coIheita mecanizada estabelecido por Bonetti (1983), para quem deve ser superior a $65 \mathrm{~cm}$ de altura. Porém, de acordo com Souza et al. (2010), plantas com porte alto poderão sofrer com o processo de acamamento e dificultar a colheita.

Figura 1. Influência de doses de gesso agrícola na altura de planta da cultura da soja. Tangará da Serra (MT), UNEMAT, safra 2014/2015.

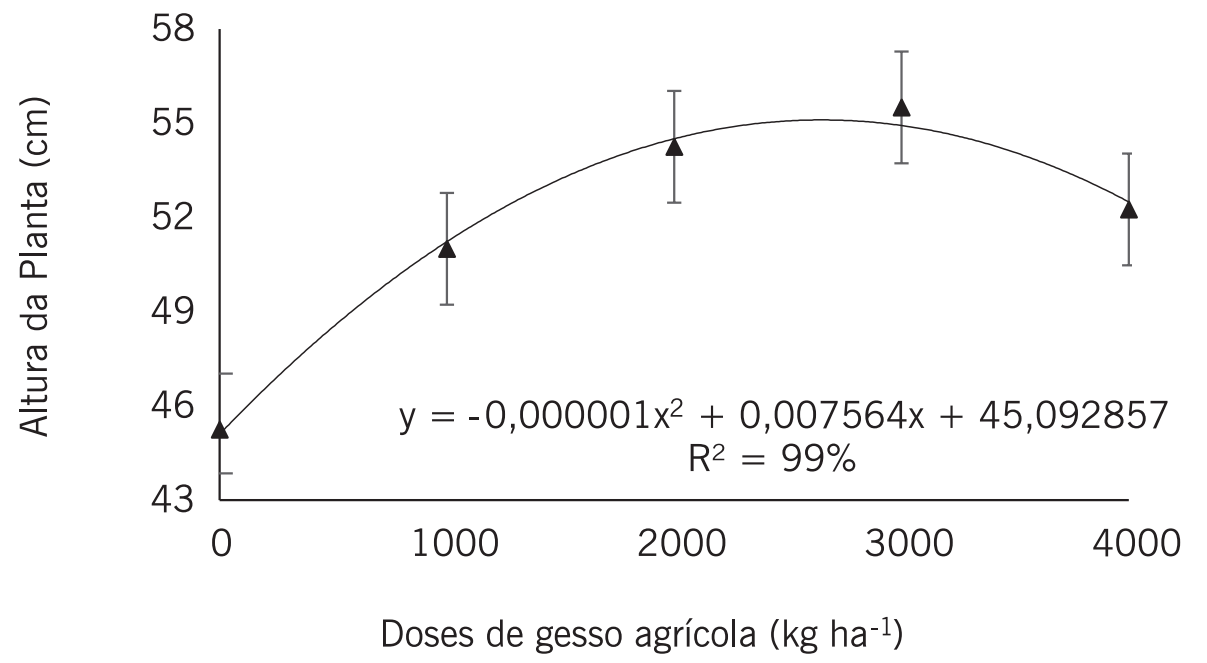

Fonte: Elaboração dos autores.

Resultados diferentes foram obtidos por Zapparoli et al. (2013), que verificaram que a altura de planta não apresentou diferenças entre as doses de gesso utilizadas $\left(0,2,4,6\right.$, 8 e 10 t ha-1 $\left.^{-1}\right)$ em um LATOSSOLO VERMELHO Amarelo Alumínico de textura arenosa. Tais resultados podem ser atribuídos ao fato de o experimento ter sido conduzido em casa de vegetação, onde as plantas não sofreram com déficit hídrico.

Entretanto, valores superiores ao do presente estudo foram obtidos por Souza et al. (2010), que observaram altura de planta de $85 \mathrm{~cm}$ com aplicação de $2 \mathrm{t} \mathrm{ha}{ }^{-1}$ de gesso agrícola em LATOSSOLO VERMELHO Distroférrico. Esses pesquisadores justificaram que o melhor desenvolvimento das plantas na dose de $2 \mathrm{t} \mathrm{ha}^{-1}$ de gesso agrícola foi em decorrência da melhoria do ambiente de exploração radicular, em razão da maior agregação do solo, redução de elementos tóxicos como o alumínio e favorecimento dos atributos químicos e físicos do solo.

O número médio de vagens por planta (Figura 2) foi superior nas doses de $2 \mathrm{t} \mathrm{ha}^{-1}(114,25$ vagens), 3 e $4 \mathrm{t} \mathrm{ha}^{-1}$ (109,75 vagens), e o menor valor verificado na dose zero (88,75 vagens). Foi observado aumento de $28,73 \%$ de vagens por planta com aplicação de $2 \mathrm{t} \mathrm{ha}^{-1}$ de gesso comparado à dose zero. Souza et al. (2010) não verificaram efeitos do gesso agrícola ( $2 \mathrm{t} \mathrm{ha}^{-1}$ ) no número de vagens. Moda et al. (2013) também não verificaram acréscimo de produção da cultura da soja com aplicação de 0, 30, 60, 90 e $120 \mathrm{~kg} \mathrm{ha}^{-1}$ de enxofre, tendo como fonte o gesso agrícola em um LATOSSOLO VERMELHO Eutrófico. 
Figura 2. Número médio de vagens por planta em função de doses de gesso agrícola aplicado na cultura da soja. Tangará da Serra (MT), UNEMAT, safra 2014/2015.

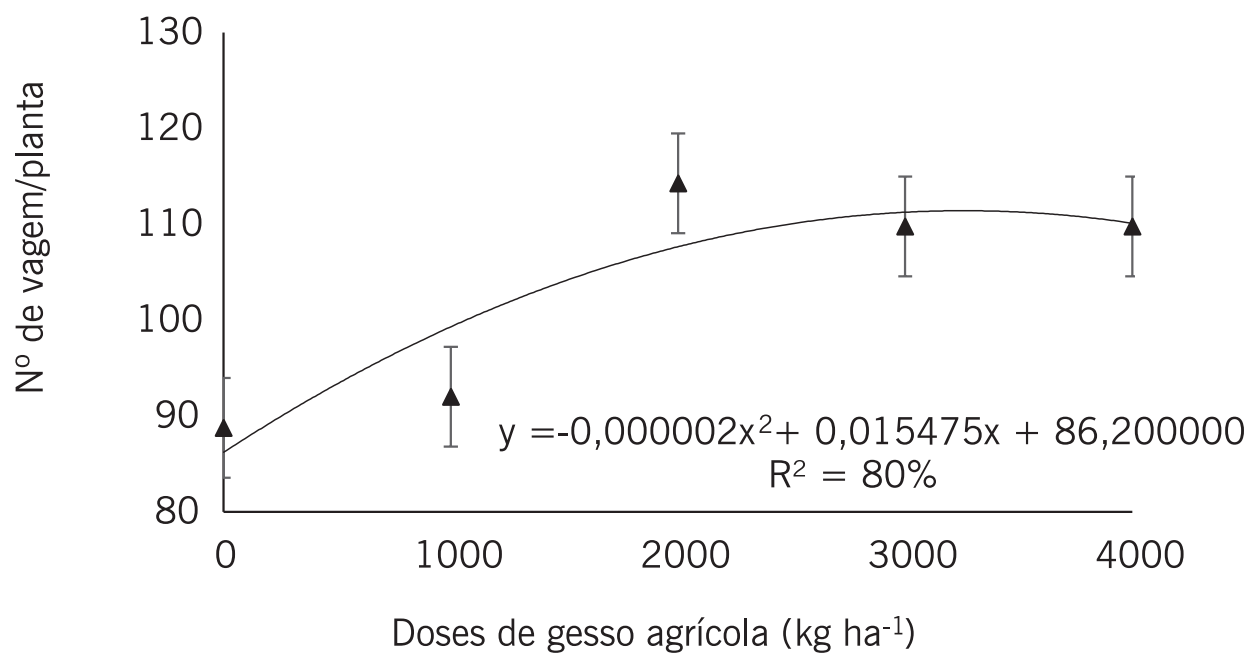

Fonte: Elaboração dos autores.

Em estudo conduzido em Sapezal (MT) em um LATOSSOLO FRANCO-Argilo-Arenosa, Júnior et al. (2015) verificaram incrementos de produção com aplicação de gesso agrícola, no entanto, a dose máxima aplicada foi de $1 \mathrm{t} \mathrm{ha-1}$, em que foram observadas cerca de 72 vagens por planta. Porém, foi $22 \%$ inferior ao número de vagens observadas no presente estudo (92 vagens) com a mesma dose de gesso agrícola.

As plantas submetidas à dose de gesso de $2 \mathrm{t} \mathrm{ha}^{-1}$ apresentaram os menores valores da altura da primeira vagem (média de $6 \mathrm{~cm}$ ), enquanto o tratamento zero foi $8 \mathrm{~cm}$ (Figura 3). Os valores da altura da primeira vagem foram inferiores aos preconizados por Mello (1988) para maior eficiência da colheita mecânica, que é de $13 \mathrm{~cm}$. Queiros (2005) e Souza et al. (2010) não verificaram diferenças na altura da primeira vagem na condição de presença ou ausência de gesso agrícola.

Figura 3. Altura da primeira vagem das plantas em função de doses de gesso agrícola aplicado na cultura da soja. Tangará da Serra (MT), UNEMAT, safra 2014/2015.

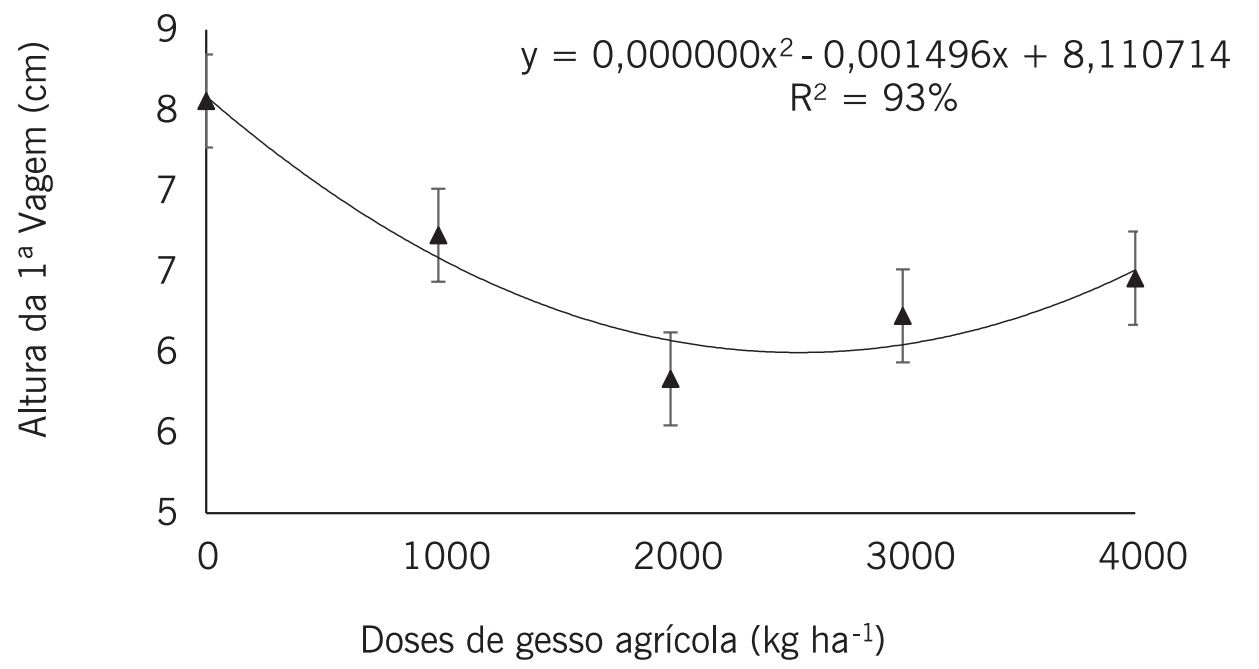

Fonte: Elaboração dos autores. 
Além do número de nós (Figura 4), a altura da planta também foi maior no tratamento de $2 \mathrm{t}$ $h^{-1}$ e, a partir da relação entre essas duas variáveis, verificou-se espaçamento entre os nós de 3,77; 3,$71 ; 3,10 ; 3,76$ e 3,54 cm paras as doses de 0, 1, 2, 3 e 4 t ha-1 de gesso agrícola, respectivamente.

Figura 4. Número de nós por planta em função de doses de gesso agrícola aplicado na cultura da soja. Tangará da Serra (MT), UNEMAT, safra 2014/2015.

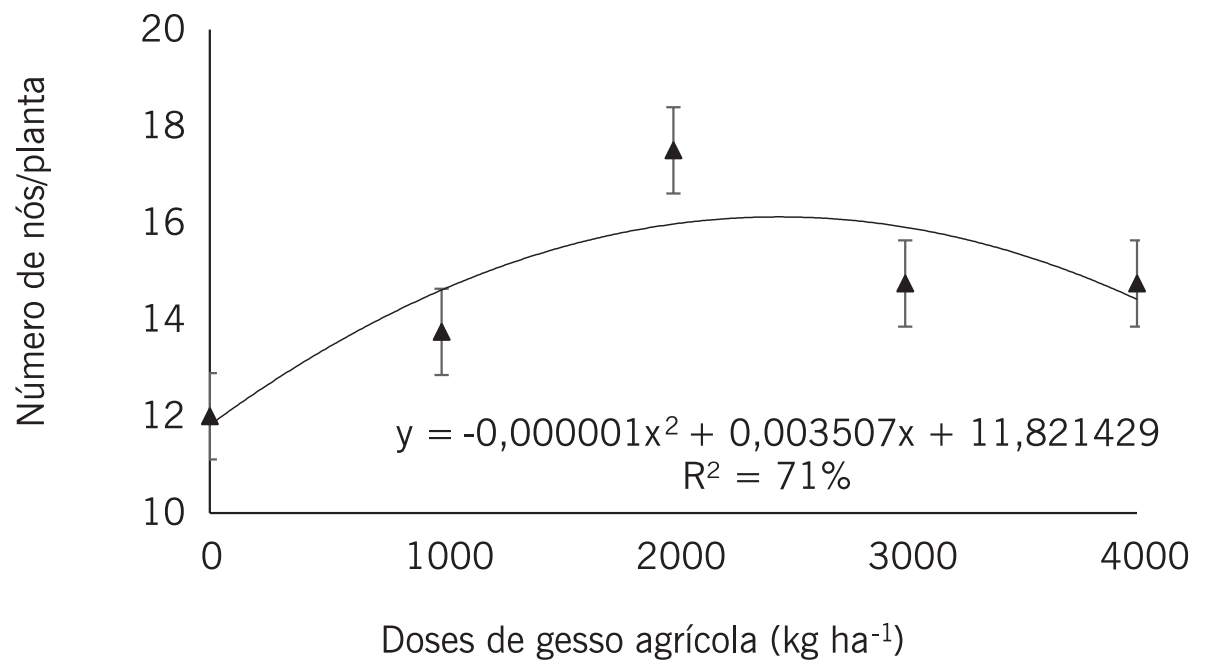

Fonte: Elaboração dos autores.

O melhor desenvolvimento da cultura da soja em relação ao gesso nos permite entender que ocorre melhoria da qualidade do ambiente de exploração radicular da planta propiciando condições favoráveis ao seu desenvolvimento. Esses resultados corroboram as afirmações de Caires et al. (2001) e Oliveira et al. (2009), que relataram que o efeito benéfico do gesso se dá por este ser um condicionador de solo capaz de neutralizar o alumínio tóxico no subsolo e, assim, permitir maior área de exploração das raízes, tendo como efeito na planta um menor estresse hídrico, gerando melhor desenvolvimento das características vegetativas e reprodutivas (RAMPIM et al., 2011).

A massa de 100 grãos também apresentou-se superior na dose de $2 \mathrm{t} \mathrm{ha}^{-1}$ de gesso $(25 \mathrm{~g}) \mathrm{em}$ comparação com a testemunha (18 g), representando um acréscimo de cerca de $39 \%$ na massa de grãos (Figura 5). Resultados inferiores foram observados por Júnior et al. (2015), que obtiveram aumento de cerca de $9 \%$ na massa de grãos na dose de $1 \mathrm{t} \mathrm{ha}^{-1}$ em relação a dose zero. No presente estudo, a comparação com a mesma dose apresentou acréscimo de $11 \%$. Broch et al. (2011) também verificaram acréscimo na massa de grão com aplicação de gesso agrícola. 
Figura 5. Massa de 100 grãos em função de doses de gesso agrícola aplicado na cultura da soja. Tangará da Serra (MT), UNEMAT, safra 2014/2015.

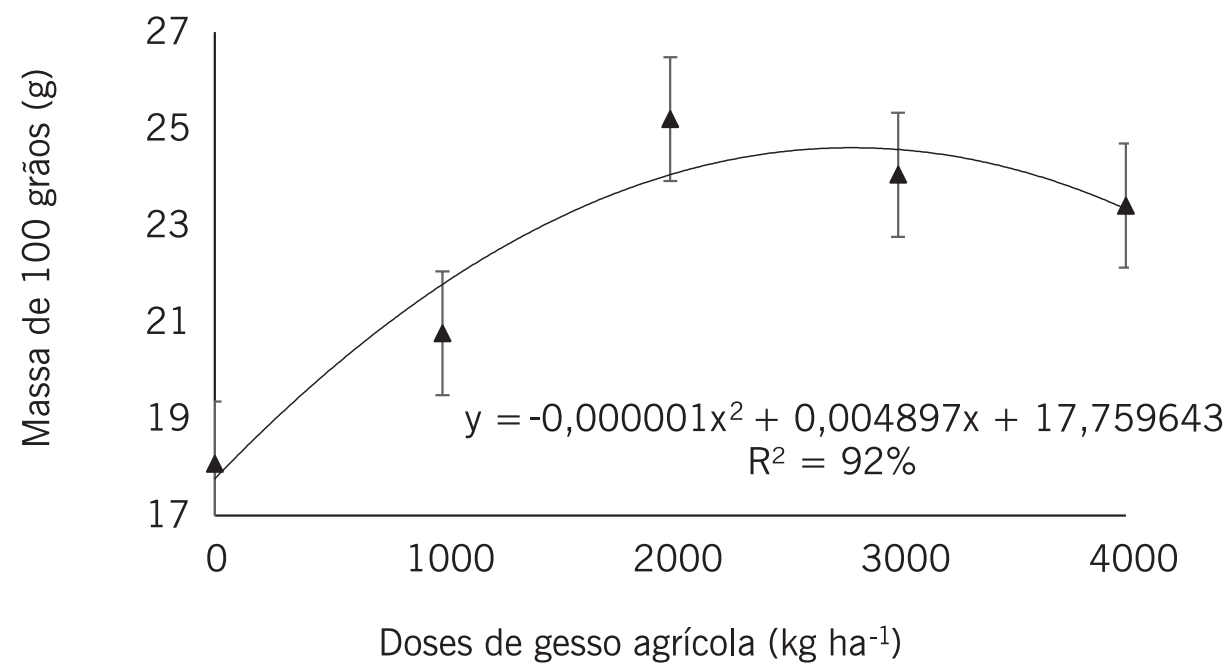

Fonte: Elaboração dos autores.

Não ocorreram períodos com veranicos (falta de chuva por determinados períodos durante a safra), entretanto, a saturação de alumínio no solo estava acima do recomendado (20 \%) por Sousa e Lobato (2004), portanto, atribuem-se respostas significativas da soja quanto à aplicação do gesso agrícola. No entanto, Pauletti et al. (2014) afirmaram que doses elevadas de gesso agrícola sob condições de boa disponibilidade hídrica podem prejudicar a produção da cultura da soja por induzir a deficiência nutricional de magnésio, promovendo a redução da produtividade e massa de grãos nas doses acima de $3 \mathrm{t} \mathrm{ha-1}$ de gesso.

A produtividade foi fortemente influenciada pelas doses de gesso agrícola aplicadas em superfície no solo, partindo de $985,00 \mathrm{~kg} \mathrm{ha}^{-1}$ na dose zero para 3.422,25 $\mathrm{kg} \mathrm{ha}^{-1}$ na melhor dose, de $2 \mathrm{t} \mathrm{ha}^{-1}$ (Figura 6 ), incrementos de cerca de $250 \%$ a mais de produtividade. Resultados inferiores foram observados por Júnior et al. (2015), que tiveram acréscimos de 460,00 kg ha-1 com aplicação de 1 t ha-1 de gesso, sendo que, com essa mesma dose no presente estudo, verificaram-se incrementos de $1.179 \mathrm{~kg} \mathrm{ha}^{-1}$.

Figura 6. Produtividade de soja em função de doses de gesso agrícola aplicado na superfície do solo. Tangará da Serra (MT), UNEMAT, safra 2014/2015.

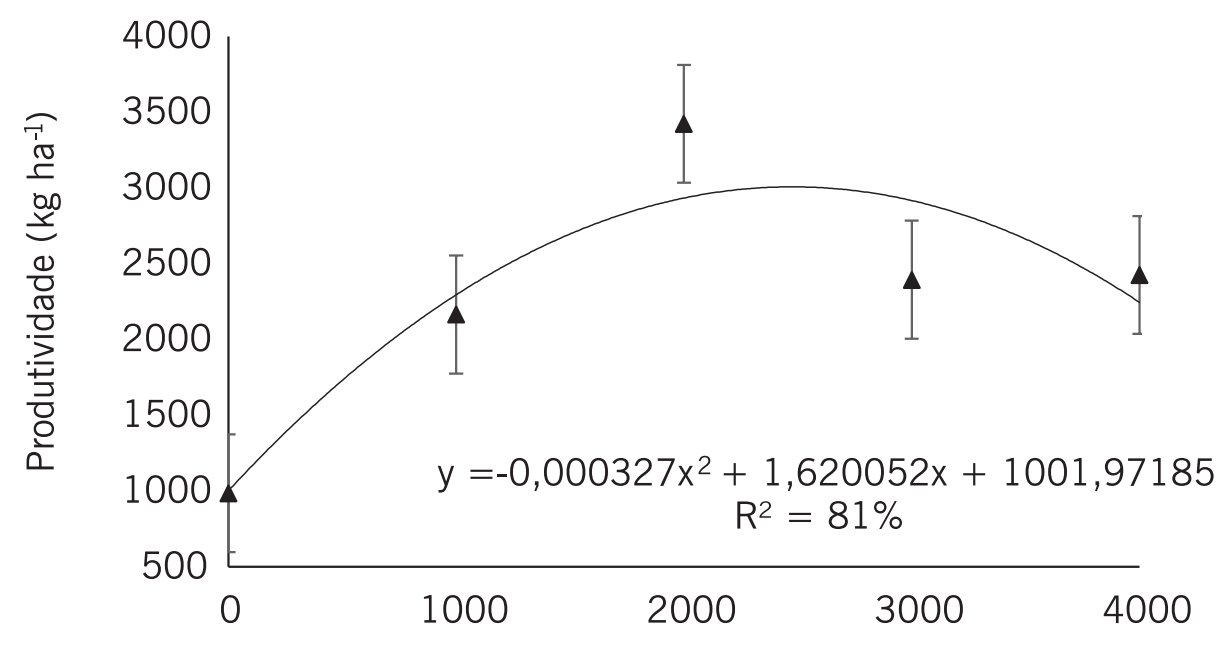

Doses de gesso agrícola $\left(\mathrm{kg} \mathrm{ha}^{-1}\right)$

Fonte: Elaboração dos autores. 
Em relação à produtividade de grãos de soja, Broch et al. (2011) relataram que a cultura apresenta boa resposta à aplicação de enxofre, pois esse é importante para formação de grãos, entretanto, a exigência da planta acaba não sendo totalmente suprida em razão da baixa concentração nos solos do Cerrado, exigindo sua reposição que, segundo Mascarenhas et al. (2013), são necessários $10 \mathrm{~kg}$ ha-1 de S para produzir cerca de $3.000 \mathrm{~kg} \mathrm{ha}^{-1}$ de grãos.

Cardoso, Peres e Lambert (2014) testando os efeitos do gesso agrícola na cultura da soja em um LATOSSOLO VERMELHO Distroférrico tiveram problemas com déficit hídrico durante a condução da pesquisa, contudo observaram incrementos de produtividade em função da aplicação do gesso. De acordo com os autores acima, isso ocorreu pela ação condicionadora do gesso agrícola no solo, que age neutralizando o alumínio em profundidade, liberando cálcio, enxofre e lixiviando nutrientes no perfil, além de atuar como descompactador do solo.

Em contrapartida, Caires et al. (2003) não observaram incrementos na produção de soja quando submetida ao efeito de doses de gesso agrícola. Cabe ressaltar que durante a condução desta pesquisa não ocorreu déficit hídrico e a concentração de alumínio tóxico no solo ao final do ciclo da soja era de 2 a $5 \mathrm{mmol}_{\mathrm{c}} \mathrm{dm}^{-3}$, nível considerado baixo para solos do cerrado conforme Sousa e Lobato (2004).

Quanto à produção da soja submetida a doses de gesso em sucessão ao milho, Caires et al. (2011) observaram que a soja não apresentou respostas produtivas em função da aplicação do gesso, porém ocorreu maior acúmulo de fósforo (P) e enxofre (S) nas folhas. Além disso, esses autores relatam que a soja não responde à aplicação de gesso agrícola em solos com adequada disponibilidade de cálcio, magnésio, enxofre e fósforo, visto que essa cultura é bastante eficiente na absorção desses nutrientes.

Visto essas diferentes respostas da cultura da soja, justifica-se a importância de pesquisas como esta, realizada em uma região de grande participação na produção de soja do estado de Mato Grosso. Para melhor explicar a relação entre os parâmetros analisados no presente estudo, foi possível verificar correlações negativas e positivas entre as variáveis analisadas (Tabela 4).

Tabela 4. Matriz de correlação linear de Pearson das variáveis altura de planta (AP), diâmetro do caule (DC), número de vagens por planta (NVP), altura de inserção da primeira vagem $\left(A 1^{a} \mathrm{~V}\right)$, número de nós $(\mathrm{NN})$, massa de 100 grãos (MCG) e produtividade (PROD). Tangará da Serra (MT), UNEMAT, safra 2014/2015.

\begin{tabular}{lccccccc}
\hline \multirow{2}{*}{ Variáveis } & \multicolumn{7}{c}{ Coeficiente de correlação de Pearson } \\
\cline { 2 - 7 } & AP & DC & NVP & A1 ${ }^{\text {aV }}$ & NN & MCG & PROD \\
\hline AP & 1 & & & & & & \\
DC & $0,3750^{\text {ns }}$ & 1 & & & & & \\
NVP & $0,65367^{*}$ & $0,39201^{\text {ns }}$ & 1 & & & & \\
A1 $^{\text {aV }}$ & $-0,5985^{*}$ & $-0,37184^{\text {ns }}$ & $-0,75081^{*}$ & 1 & & & \\
NN & $0,59994^{*}$ & $0,35492^{\text {ns }}$ & $0,69324^{*}$ & $-0,65939^{*}$ & 1 & & \\
MCG & $0,67966^{*}$ & $0,52534^{* *}$ & $0,82004^{*}$ & $-0,68032^{*}$ & $0,69061^{*}$ & 1 & \\
PROD & $0,67246^{*}$ & $0,33665^{\text {ns }}$ & $0,77724^{*}$ & $-0,76157^{*}$ & $0,83063^{*}$ & $0,82909^{*}$ & 1 \\
\hline
\end{tabular}

*Significativo a $1 \%(p \leq 0,01) . * *$ Significativo a $5 \%(p \leq 0,05)$. ns não significativo.

Fonte: Elaboração dos autores.

As correlações negativas das variáveis indicam que à medida que uma variável aumenta, a outra diminui. Por outro lado, as correlações positivas indicam que uma variável aumenta e a outra apresenta o mesmo comportamento (ASCARI et al., 2015). É importante ressaltar que a produtividade apresentou correlação positiva com altura de planta, número de vagens por planta, número de nós 
e massa de 100 grãos e correlação negativa com altura de inserção da primeira vagem. Não ocorreu correlação significativa de diâmetro do caule com altura de planta, número de vagem por planta, altura de inserção da primeira vagem, número de nós e produtividade.

A partir desses dados, percebe-se a importância que as características vegetativas e reprodutivas exercem sobre a produtividade final da cultura, sendo esses aspectos importantes nas tomadas de decisões e escolha da cultivar.

\title{
Conclusão
}

A soja apresentou resposta positiva à aplicação de gesso agrícola em superfície do solo, onde a dose de $2 \mathrm{t} \mathrm{ha}^{-1}$ promoveu o melhor desenvolvimento das características agronômicas e produtivas. A produtividade máxima de soja observada foi de $3.422 \mathrm{~kg} \mathrm{ha}^{-1}$ de grãos.

\section{Agronomic and productive development of soybean under different doses of phosphogypsum}

\begin{abstract}
Soy is one of the main crops that drives Brazilian agribusiness, therefore it is necessary to adopt techniques that influence the improvement of soil quality, such as gypsum. This study aimed to investigate the influence of phosphogypsum doses in vegetative and reproductive development of soybean crop. The experiment was conducted at the University of Mato Grosso, Campus Tangara da Serra. The experimental design was a randomized block design (RBD) with five treatments, with 0,1 , 2, 3 and $4 \mathrm{t} \mathrm{ha}^{-1}$ of phosphogypsum, with four replications. Liming and gypsum at 30 and 60 days, respectively, were carried out before the seeds were sown. The seeds were sown in the second half of November with the cultivar P98Y30 in soil fertilized in the groove. Evaluations were performed on 10 random plants in the developmental stage $R_{9}$. It was observed that the variables plant height, first pod height, number of nodes, number of pods per plant, weight of 100 grains and yield were influenced significantly by the levels of gypsum, at which the best results occurred at a dose of $2 \mathrm{t} \mathrm{ha}^{-1}$, however, the stem diameter was not affected. Based on these, it was found that the dose of $2 \mathrm{t} \mathrm{ha}^{-1}$ gypsum had the best effect on vegetative growth and reproductive soybeans.
\end{abstract}

Keywords: Glycine max L. Gypsum. Yield.

\section{Referências}

ASCARI, J. P.; SANTOS, E. S.; MENDES, I. R. N.; DIAS, L. D. E.; INOUE, M. H.; MARCO, K. Formas de adubação do sorgo granífero em semeadura tardia. Revista Nucleus, Ituverava, v. 11, n. 1, p. 7-14, 2015. Disponível em: <http://www.nucleus.feituverava.com.br/index.php/nucleus/article/ view/1166/1725>. Acesso em: 20 abr. 2016.

BONETTI, L. P. Cultivares e seu melhoramento genético. In: VERNETTI, F. J. Soja: genética e melhoramento. Campinas: Fundação Cargill, 1983. p. 741-794.

BRASIL. Ministério da Agricultura, Pecuária e Abastecimento (MAPA). Regras para análise de sementes. Brasília: SNDA/DNDV/CLAV, 2009. 399 p. 
BROCH, D. L.; NOLLA, A.; QUIQUI, E. M. D.; POSSENTI, J. C. Influência no rendimento de plantas de soja pela aplicação de fósforo, calcário e gesso em um latossolo sob plantio direto. Revista Ciências Exatas e Naturais, Guarapuava, v. 10, n. 2, p. 211-220, 2008. Disponível em: < http://revistas. unicentro.br/index.php/RECEN/article/viewFile/709/882 > . Acesso em: 20 abr. 2016.

BROCH, D. L.; PAVINATO, P. S.; POSSENTTI, J. S.; MARTIN, T. N.; QUIQUI, E. M. D. Produtividade da soja no cerrado influenciada pelas fontes de enxofre. Revista Ciência Agronômica, Fortaleza, v. 42, n. 3, p. 791-796, 2011. Disponível em: <http://www.scielo.br/scielo.php?script=sci_arttext\&pid $=$ S1806-66902011000300027 > . Acesso em: 27 abr. 2016.

CAIRES, E. F.; BLUM, J.; BARTH, G.; GARBUIO, F. J.; KUSMAN, M. T. Alterações químicas do solo e resposta da soja ao calcário e gesso aplicados na implantação do sistema plantio direto. Revista Brasileira de Ciência do Solo, Viçosa, v. 27, n. 2, p. 275-286, 2003. Disponível em: <http://www. scielo.br/scielo.php?pid=S0100-06832003000200008\&script $=$ sci_abstract\&tIng $=p t>$. Acesso em: 27 abr. 2016.

CAIRES, E. F.; FONSECA, A. F.; FELDHAUS, I. C.; BLUM, J. Crescimento radicular e nutrição da soja cultivada no sistema plantio direto em resposta ao calcário e gesso na superfície. Revista Brasileira de Ciência do Solo, Viçosa, v. 25, n. 4, p. 1029-1040, 2001. Disponível em: <http://www.scielo. br/pdf/rbcs/v25n4/25.pdf>. Acesso em: 30 mar. 2016.

CAIRES, E. F.; GARBUIO, F. J.; CHURKA, S.; BARTH, G.; CORREAA, J. C. L. Effects of soil acidity amelioration by surface liming on no-till corn, soybean, and wheat root growth and yield. European Journal of Agronomy, v. 28, n. 1, p. 57-64, 2008. Disponível em: <http://www.sciencedirect.com/ science/article/pii/S1161030107000524>. Acesso em: 24 abr. 2016.

CAIRES, E. F.; MASCHIETTO, E. H. G.; GARBUIO, F. J.; CHURKA, S.; JORIS, H. A. Surface application of gypsum in low acidic Oxisol under no-till cropping system. Scientia Agricola, Piracicaba, v. 68, n. 2, p. 209-216, 2011. Disponível em: <http://www.scielo.br/scielo.php?script=sci_arttext\&pid=S0103-90162011000200011 > . Acesso em: 30 mar. 2016.

CARDOSO, J. A. E.; PERES, G. C. M.; LAMBERT, R. A. Influência da aplicação de calcário e gesso na cultura da soja (Glycine max (L.) Merrill). Enciclopédia Biosfera, Goiânia, v. 10, n. 18, p. 19801987, 2014. Disponível em: <http://www.conhecer.org.br/enciclop/2014a/AGRARIAS/influencia. pdf $>$. Acesso em: 27 jan. 2016.

CARVALHO, M. C. S.; NASCENTE, A. S. Limestone and phosphogypsum effects on soil fertility, soybean leaf nutrition and yield. African Journal of Agricultural Research, v. 9, n. 17, p. 13661383, 2014. Disponível em: <http://www.academicjournals.org/journal/AJAR/article-abstract/ AODB5BB44144>. Acesso em: 24 abr. 2016.

CHERUBIN, M. R. et al. Influência da aplicação de gesso agrícola na produtividade da cultura de soja em Latossolo. In: CONGRESSO BRASILEIRO DE CIENCIA DO SOLO, 33., 2010, Uberlândia. MG. Anais... Congresso Brasileiro de Ciência do Solo. Uberlândia, 2010.

Companhia Nacional de Abastecimento (CONAB). Acompanhamento da safra brasileira de grãos: Oitavo levantamento, Safra 2015/16. Brasília: CONAB, v. 3, n. 8, 2016. p. 127-138. 
DALLACORT, R.; MARTINS, J. A.; INOUE, M. H.; FREITAS, P. S. L.; COLETTI, A. J. Distribuição das chuvas no município de Tangará da Serra, médio norte do Estado de Mato Grosso, Brasil. Acta Scientiarum Agronomy, Maringá, v. 33, n. 2, p. 193-200, 2011. Disponível em: <http://www.scielo.br/ scielo.php?script=sci_arttext\&pid=S1807-86212011000200001 >. Acesso em: 24 abr. 2016.

Empresa Brasileira de Pesquisa Agropecuária (EMBRAPA). Manual de métodos de análise de solo. 2. ed. Brasília: Embrapa Solos, 2011. 230 p. (Documentos, 132).

Empresa Brasileira de Pesquisa Agropecuária (EMBRAPA). Sistema brasileiro de classificação de solos. 3. ed. Brasília: Embrapa informação tecnológica, 2013. 353 p.

ERNANI, P. R.; RIBEIRO, M. S.; BAYER, C. Modificações químicas em solos ácidos ocasionadas pelo método de aplicação de corretivos da acidez e de gesso agrícola. Scientia Agricola, Piracicaba, v. 58, n. 4 , p. 825-831, 2001.

FERREIRA, D. F. Sisvar: a computer statistical analysis system. Ciência e Agrotecnologia, Lavras, v. 35, n. 6, p. 1039-1042, 2011.

MARCHIORO JÚNIOR, M. A.; GIEBELMEIER, C. G.; MARIANO, D. C.; SILVA, C. S.; OKUMURA, R. $\mathrm{S}$. Produção de grãos de soja no cerrado em função de gesso aplicado no solo. Enciclopédia Biosfera, Goiânia, v. 11, n. 21, p. 1220-1229, 2015. Disponível em: <http://www.conhecer.org.br/enciclop/2015b/agrarias/PRODUCAO\%20DE\%20GRAOS\%20DE\%20SOJA. pdf> . Acesso em: 02 abr. 2016.

MASCARENHAS, H. A. A.; ESTEVES, J. A. F.; WUTKE, E. B.; RECO, P. C.; LEÃO P. C. L. Deficiência e toxicidade visuais de nutrientes em soja. Revista Nucleus, Ituverava, v. 10, n. 2, p. 281-306, 2013. Disponível em: <http://www.nucleus.feituverava.com.br/index.php/nucleus/article/view/974>. Acesso em: 24 abr. 2016.

MELLO, L. M. M. Efeitos de diferentes sistemas de preparo do solo na cultura da soja (Glycine Max (L). Merrill) e sobre algumas propriedades de um Latossolo Vermelho Escuro de cerrado. 1998, 132 f. Tese (Doutorado em Agronomia - Energia na Agricultura) - Faculdade de Ciência Agronomia, Universidade Estadual Paulista, Botucatu (SP), 1998.

MODA, L. R.; BORGES, B. M. M. N.; FLORES, E. A.; SANTOS, C. L. R.; PRADO, R. M.; SOUSA, J. I. Gessagem na cultura da soja no sistema de plantio direto com e sem adubação potássica. Revista AgroAmbiente, Boa Vista, v. 7, n. 2, p. 129-135, 2013. Disponível em: <https://revista.ufrr.br/agroambiente/article/view/948>. Acesso em: 06 maio 2016.

OLIVEIRA, I. P.; COSTA, K. A. P.; FAQUIN, V.; MACIEL, G. A.; NEVES, B. P.; MACHADO, E. L. Efeitos de fontes de cálcio no desenvolvimento de gramíneas solteiras e consorciadas. Ciência e Agrotecnologia, Lavras, v. 33, n. 2, p. 592-598, 2009. Disponível em: < http://www.scielo.br/scielo.php?scrip$\mathrm{t}=$ sci_arttext\&pid=S1413-70542009000200036>. Acesso em: 06 maio 2016.

PAULETTI, V.; PIERRI, L.; RANZAN, T.; BARTH, G.; MOTTA, A. C. V. Efeitos em longo prazo da aplicação de gesso e calcário no sistema de plantio direto. Revista Brasileira de Ciência do Solo, Viçosa, v. 38, n. 2, p. 495-505, 2014. Disponível em: <http://www.scielo.br/scielo.php?script=sci_arttext\&pid=S0100-06832014000200014>. Acesso em: 24 abr. 2016. 
QUEIROZ, R. P. Adubação fosfatada corretiva e gesso no plantio direto de soja e sorgo sobre pastagem degradada na região do cerrado. São Paulo, 2005. 70 f. Dissertação (Mestrado em Agronomia - Sistemas de Produção) - Faculdade de Engenharia de Ilha Solteira, Universidade Estadual Paulista.

RAIJ, B. V. Gesso na Agricultura. Campinas: Instituto Agronômico, 2008. 233p.

RAMOS, L. A.; NOLLA, A.; KRONDORFER, G. H.; PEREIRA, H. S.; CAMARGO, M. S. Reatividade de corretivos da acidez e condicionadores de solo em colunas de lixiviação. Revista Brasileira de Ciência do Solo, Viçosa, v. 30, n. 5, p. 849-857, 2006. Disponível em: <http://www.dpv24.iciag.ufu.br/ Silicio/Arquivos\%20Papers/2006\%20-\%20RBCS.\%20v30.\%20-\%20Lucelia,\%20Si\%20x\%20lixiviacao.pdf > . Acesso em: 02 maio 2016.

RAMPIM, L.; LANA, M. C.; FRANDOLOSO, J. F.; FONTANIVA, S. Atributos químicos de solo e resposta do trigo e da soja ao gesso em sistema semeadura direta. Revista Brasileira de Ciência do Solo, Viçosa, v. 35, n. 5, p. 1687-1698, 2011. Disponível em: <http://www.scielo.br/scielo.php?scrip$\mathrm{t}=$ sci_arttext\&pid=S0100-06832011000500023 > . Acesso em: 24 abr. 2016.

SORATTO, R. P.; CRUSCIOL, C. A. C. Métodos de determinação de cálcio e magnésio trocáveis e estimativa do calcário residual em um Latossolo submetido à aplicação de calcário e gesso em superfície. Revista Brasileira de Ciência do Solo, Viçosa, v. 32, n. 2, p. 663-673, 2008.

SOUSA, D. M. G. Resposta das culturas à adição de gesso agrícola. In: REUNIÃO BRASILEIRA DE FERTILIDADE DO SOLO E NUTRIÇÃO DE PLANTAS, 26., 2004, Lages, SC. Anais... FERTBIO, 2004. (Trabalho completo CDROM).

SOUSA, D. M. G.; LOBATO, E. Cerrado: correção do solo e adubação. 2. ed. Brasília: Embrapa Cerrados, $2004,416 \mathrm{p}$.

SOUZA, F. R.; ROSA JUNIOR, E. J.; FIETZ, C. R.; BERGAMIN, A. C.; VENTUROSO, L. R.; ROSA, Y. B. C. J. Atributos físicos e desempenho agronômico da cultura da soja em um Latossolo VermeIho Distroférrico submetido a dois sistemas de manejos. Ciência e Agrotecnologia, Lavras, v. 34, n. 6, p. 1357-1364, 2010. Disponível em: <http://www.scielo.br/scielo.php?script=sci_arttext\&pi$\mathrm{d}=$ S1413-70542010000600001 > . Acesso em: 02 maio 2016.

TANAKA, R. T.; MASCARENHAS, H. A. A. Resposta da soja à aplicação de gesso agrícola. 0 Agronômico, Campinas, v. 54, n. 2, p. 27-28, 2002. Disponível em: <http://www.iac.sp.gov.br/publicacoes/agronomico/pdf/542_27_it6_gesso.pdf>. Acesso em: 18 abr. 2016.

ZAPPAROLI, R. A.; BONADIO, M. L.; GOMES, C. J. A.; NASCIMENTO, D. M. D.; MARCHIONE, M. S.; BERNA, R.; CASTRO, A. M. C. Associação calcário e gesso na cultura da soja e nas características químicas do solo com alta saturação em alumínio. Cultivando o Saber, Cascavel, v. 6, n. 4, p. 74- 84, 2013. Disponível em: <https://www.fag.edu.br/upload/revista/cultivando_o_saber/52b62dd496f39.pdf>. Acesso em: 04 maio 2016.

\section{Histórico editorial:}

Submetido em: 13/06/2016.

Aceito em: 22/09/2016. 
Como citar:

ABNT

ASCARI, J. P.; MENDES, I. R. N. Desenvolvimento agronômico e produtivo da soja sob diferentes doses de gesso agrícola. Revista Agrogeoambiental, Pouso Alegre, v. 9, n. 4, p. 47-60, out./dez.

Doi: http://dx.doi.org/10.18406/2316-1817v9n420171014

$\underline{A P A}$

ASCARI, J. P. \& MENDES, I. R. N. (2017). Desenvolvimento agronômico e produtivo da soja sob diferentes doses de gesso agrícola. Revista Agrogeoambiental, 9 (4), 47-60.

Doi: http://dx.doi.org/10.18406/2316-1817v9n420171014

ISO

ASCARI, J. P. e MENDES, I. R. N. Desenvolvimento agronômico e produtivo da soja sob diferentes doses de gesso agrícola. Revista Agrogeoambiental, 2017, vol. 9, n. 4, pp. 47-60. Eissn 2316-1817.

Doi: http://dx.doi.org/10.18406/2316-1817v9n420171014

VANCOUVER

Ascari JP, Mendes IRN. Desenvolvimento agronômico e produtivo da soja sob diferentes doses de gesso agrícola. Rev agrogeoambiental. 2017 out/dez; 9(4): 47-60.

Doi: http://dx.doi.org/10.18406/2316-1817v9n420171014 